\title{
A propósito de A LITERATURA PORTUGUESA E AS NOVAS ORIENTAÇÕES CRfTICAS
}

\author{
Intervençăo de JERUSA PIRES FERREJRA \\ (Professor da Universidade Federal da Bahia)
}

\section{Caros Colegas,}

Quero registrar, ao lado do contentamento de estarmos juntos a presença de todo um mundo de perplexidades; bichos da terra tão pequenos nós e o nosso conjunto de inquietações. Primeiramente a que resulta de ser professores de Literatura, quando se delineiam de saida os problemas:

a) Diversidade de aproximação ao objeto de arte, enquanto tal.

b) Critérios culturais e situaçăo que nos permita definir e adequar este objeto.

Sugestivo é o fato de que esta perplexidade vai transparecendo aqui, a cada passo, nas múltiplas referências colocadas a salvar, recuperar, defesa, crise, que parecem mesmo ser as significações dominantes do nosso situar-se.

Partindo, portanto, para um problema dentre os multos que nos envolvem e, cabendo-nos discutir a comunicação da Prof.' Yara Frateschi Vieira, diremos que "A Literatura Portuguesa e as Novas Orientações Criticas" sugere a adoção de uma estratégia ou a revisão sintese de algumas táticas. Abrangente como propósito de crítica da crítica mas visando sobretudo um posicionamento diante do trabalhar com textos de Literatura, e no caso, a Portuguesa.

Declara a autora da comunicação a sua opção por discutir o caminho do recurso a Lingúística como disciplina auxiliar em busca de diagnóstico ou interpretaçăo do texto, passando em seguida a analisar as investidas sobre 
a especificldade do literário, apontando como as várias abordagens críticas nem sempre são criticas mas sobretudo descritivas. Acho que não é bem assim, quando a partir da sugestāo etimológica da palavra critica, a propria escolha já indica uma tal operação.

No entanto, um importante problema teórico é colocado em discussão quando se trata do recurso freqüente e outras epistemologias para o que se pretenda como caminho, seja além disto para a psico, socio ou critica filosófica. Deve-se sempre ressaltar (lembrando a liçāo trazida e nāo esgotada de Wellek e Warren em sua clássica "Teoria da Literatura") que, o que importa é que se entendam estes recursos como afluências, e mesmo como confluéncias para a aferição de uma realidade maior e especifica, evitando que se transformem em meros pretextos ou que venham a substituir o alcance da prospecção, o objeto buscado quando da análise de coisa literária.

Conta a meu ver é que, nāo se podendo abrir māo de uma certa interdisciplinaridade, constata-se que não existe interdisciplinaridade sem conflitos ou contradiçōes concluindo-se que ao trabalhar com o texto literário, o que nāo se poderá fazer será privilegiar o paradigmático em qualquer instància.

Northrop Frye em "O Caminho Critico" menciona o problema do conflito da interdisciplinaridade, dizendo estar consciente para um possivel desvio do especifico da coisa buscada e menciona o fato de ter sido apontado como um crítico que extrai suas hipóteses da antropologia e da psicologia. Curioso, no entanto. é que ao longo do seu livro, termina enveredando pelos rumos que aponta como desvios e acaba muita vez por fazer Antropologia (em si mesma ampla e indefinida enquanto campo de prospecção). A autora analisa muito lucidamente este impasse tentando mostrar como ele transparece em alguns trabalhos, onde as propriedades detectadas passaram a ter estatuto de critérios, como os inoportunos de valoração estética, por exemplo. Detenho-me aqul para ver que a autora no momento em que considera os assuntos e reflete sobre táticas utilizadas, desloca-se sem. pre para a dificuldade de realizaçāo de método nos trabalhos considerados e não na dificuldade do método que discute.

Atentos devemos estar sempre para o fato de que, no campo particular da reflexāo literária, não se trata de outra coisa mais do que da crise fundamental que conhece a cultura contemporánea (cite Serge Doubrovisky em "Critica e Existêncla"] parecendo-me bem claro que:

Vemo-nos todos diante da necessidade de uma "possível ciência da Literatura" desde quando näo nos saberiamos movimentar sem o seu apoio e não teriamos porque fazê-lo, mas ao mesmo tempo não temos o exato caminho de como a ela chegar, e mesmo ai chegando, são indecisas as opçōes no que toca à sua aplicação. Assim é que me parece um tanto otimista a proposta da autora, sugerindo que se encontre a "fórmula que permita esta colaboração interdisciplinar", no caso referindo-se à aproximação lingūistica. Mas é preciso que se diga que esta perplexidade se faz a nossa 
experiência, que desta procura que compreende atos de atração ou rejeiçăo se arma o nosso aparelho crítico.

Ocorre-me que, cada um de nós, é um professor de Teoria da Literatura, que se aplica num território de expressão vernácula contando para a realizaçāo de suas tarefas como o recurso de indices contextuais e intertextuais. com a percepção de uma certa especificidade (não agora do literário em si) mas deste território pisado, que tanto quanto possivel interfira sempre no esclarecimento do que se busque demonstrar.

A "estrutura" que se procura aferir (lembrando que toda estrutura é uma hipótese e nāo uma entidade autônoma em sil), quer se operem cortes verticais na própria obra ou se estabeleça um roteiro por um conjunto, implicando em certa horizontalidade descritiva, assim o exige.

Acho que só faz sentido sermos professores de Literatura Portuguesa na medida em que o estejamos sendo, nāo fazendo dela um pretexto para a aplicação de teorias, mas cultivando e ampliando um aparelho conceitual que. por mais que negue "ismos", deve ser o resultado de permanente reflexão sobre o texto, como uma estrutura complexa, empirica e ao mesmo tempo lógica, em que se procure ser coerente com os próprios propósitos de explicar; quando se possa adequar a nossa visão de mundo à que ai vem expressa, o encontro desta percepçāo à observação objetiva de comportamentos próprios reveladores daquela cultura em um momento ou de processos e manifestaçōes que têm a ver com vários momentos de sua história, mantida uma coerência e ajuste de principios, sabendo-se que, o que está em causa, é sobretudo a dimensão específica da obra (distância interior. "profondeur poétique" ou espaço literário).

A perplexidade, reflexāo de crise, exemplo de um caminho percorrido com equivocos foi muito bem prototipada na comunicação, quando da escolha pela autora dos trabalhos de Roman Jakobson sobre Fernando Pessoa e Martim Codax que clarificam e corroboram no conjunto de suas falhas, a opinião que se seguiu até aqui, ela e eu de acordo, a necessidade de uma teoria sempre aplicada à compreensão do contextual e conseqüentemente também do intertextual. Ali pelo contrário e diga-se que se trata de um exercício de R.J., aplicado como um coelho que se tira da cartola. Faltava-lhe o conhecimento da cultura a que se referem os textos analisados, a própria sabedoria no manejo da lingua portuguesa e entāo sim "a pátria do texto é a língua portuguesa".

Observa-se sobretudo na presente comunicação o seguimento de um caminho crítico, que vem sendo colocado aqui com a intençāo de afastar equivocos, ponto em que a autora se define ao empreender um trabalho coerente, o tanto quanto possivel concillador de tendências da moderna critica lingüística, como o faz em "Niveis de Significação no Romance". Allás aproveito para fazer uma defesa desta sua posiçăo eclética que também é a que assumo.

Paul Zumthor, por exemplo, não hesita em conciliar conceitos provenientes de "estruturalismos estáticos" a conceitos generativos, da produção do 
texto à observação de seu continuo engendramento (Kristeva). Diz-nos ele que o texto é assim um acontecimento, uma informaçăo nova surgida do cruzamento de várias linhas de realidade que nele se abolem como tais. Mas elas engendram uma conotaçāo global que reproduz, de maneira em princípio imprevisivel a relação vivida dos homens ao mundo e eles mesmos. (Zumthor, Essai de Poétique Médievale. 1972, pág. 26).

Em relação ao exercicio critico da autora da comunicaçāo que se discute, depreende-se pois que o seu objetivo é observar como o romance realiza em nivel de discurso a noçāo de transformação. (Niveis de Significação no Romance, pág. 15) fazendo a conciliação do conciliável sob ponto de vista metodológico. Não recusa por exemplo a esclarecimento teórico trazido por Greimas, para além de formas e formalismos, de um Bakthine ao lado dos de Eduardo Lourenço em seu discurso poético culturalista.

Chegamos assim ao ponto teórico que me parece mais importante do problema em pauta.

Ao discutir a posição da poética gerativa considera a relativizaçāo do alcance do seu modelo e acho eu que nesta, ou em qualquer outra posição crítica assumida só poderá acontecer assim. ao adotar-se um modelo qualquer. Neste sentido é que Roland Barthes, em "Roland Barthes par lui même", hibrido e percuciente modelo para armar, montagem romanesca-retórica, subjetiva concomitantemente, vê a literatura como uma mathesis. Representa ela um mundo infinito de linguagem e como tal só captável sob modelizaçāo muito relativa.

A título de curiosidade, gostaria de mencionar o fato de os dois colegas de mesa terem escrito trabalhos sobre José Regio que revelam estuante diversidade de aproximaçāo. Luís Piva recusa a contribuição da interveniência lingüistica enquanto método, e opta pelo encontro hermenêutico com o universo do escritor.

Quanto à autora em sua "verdadeira" declaração de intenções parece excessivamente nitida que seu objetivo, em nenhum momento foi a negação da possibilidade de um trabalho conjunto de Lingüistica com o que chama de Estudos Literários, mas antes pelo contrário.

Coloca sob o seu foco trabalhos que contam este tipo de aproximação e faz a critica genérica do muito que se tem publicado sob o uso às vezes equivoco deste instrumento, aplicado no caso à Literatura Portuguesa.

Tenta alcançar determinadas investidas passiveis de reformulaçōes e sobretudo revela-nos ter a consciêncla de que o exercício formal não pode e nem deve substituir a ideologia, por um lado de quem busca, por outro de quem se oferece.

Estou plenamente de acordo, quando ao analisar processos ditos estruturalistas ou transformacionistas, ao constatar como saldo a importância, aprofundamente e rigor conseguidos pelo intercurso da LIngũística como ciência complementar, termina por colocar em fase na contextualidaḍe his- 
tórica, defendendo uma posição que permita sempre um equacionamento sócio-cultural.

Ao encerrar, toca a autora num dos problemas mais esclarecedores da verificação objetiva do processo literário, seja o da intextualidade diacrônica.

Atinando para a Importância desta intertextualidade explícita em poetas contemporâneos, como é o caso de Fiama Hasse, como poderia sem também Maria Tereza Horta, alcança a presença mágica da intulção poética na critica, a presença nunca desprezivel dos críticos poetas, que num encontro de rituais pressupõem ritos e entendimentos para além de qualquer ciência.

Seu último parágrafo $\mathbf{a}$ a linha de consonância com a minha definiçāo de investigador de Literatura, e em especial de Literatura Portuguesa, sempre voltada para a especificidade do objeto estudado em seu permanente relacionamento com indices culturais de várias ordens. 